\title{
Rethinking capacity building for knowledge mobilisation: developing multilevel capabilities in healthcare organisations
}

\author{
Roman Kislov ${ }^{1 *}$, Heather Waterman ${ }^{2}$, Gill Harvey ${ }^{1,3}$ and Ruth Boaden ${ }^{1}$
}

\begin{abstract}
Background: Knowledge mobilisation in healthcare organisations is often carried out through relatively short-term projects dependent on limited funding, which raises concerns about the long-term sustainability of implementation and improvement. It is becoming increasingly recognised that the translation of research evidence into practice has to be supported by developing the internal capacity of healthcare organisations to engage with and apply research. This process can be supported by external knowledge mobilisation initiatives represented, for instance, by professional associations, collaborative research partnerships and implementation networks. This conceptual paper uses empirical and theoretical literature on organisational learning and dynamic capabilities to enhance our understanding of intentional capacity building for knowledge mobilisation in healthcare organisations.

Discussion: The discussion is structured around the following three themes: (1) defining and classifying capacity building for knowledge mobilisation; (2) mechanisms of capability development in organisational context; and (3) individual, group and organisational levels of capability development. Capacity building is presented as a practice-based process of developing multiple skills, or capabilities, belonging to different knowledge domains and levels of complexity. It requires an integration of acquisitive learning, through which healthcare organisations acquire knowledge and skills from knowledge mobilisation experts, and experience-based learning, through which healthcare organisations adapt, absorb and modify their knowledge and capabilities through repeated practice. Although the starting point for capability development may be individual-, team- or organisation-centred, facilitation of the transitions between individual, group and organisational levels of learning within healthcare organisations will be needed.

Summary: Any initiative designed to build capacity for knowledge mobilisation should consider the subsequent trajectory of newly developed knowledge and skills within the recipient healthcare organisations. The analysis leads to four principles underpinning a practice-based approach to developing multilevel knowledge mobilisation capabilities: (1) moving from 'building' capacity from scratch towards 'developing' capacity of healthcare organisations; (2) moving from passive involvement in formal education and training towards active, continuous participation in knowledge mobilisation practices; (3) moving from lower-order, project-specific capabilities towards higher-order, generic capabilities allowing healthcare organisations to adapt to change, absorb new knowledge and innovate; and (4) moving from single-level to multilevel capability development involving transitions between individual, group and organisational learning.
\end{abstract}

Keywords: Capacity building, Capability development, Organisational capabilities, Organisational learning, Knowledge mobilisation, Knowledge translation, Knowledge transfer, Implementation, Service improvement, Facilitation

\footnotetext{
* Correspondence: roman.kislov@mbs.ac.uk

${ }^{1}$ Manchester Business School, The University of Manchester, Room D38 MBS

East, Booth Street West, Manchester M15 6PB, UK

Full list of author information is available at the end of the article
} 


\section{Introduction}

Knowledge mobilisation (KM) is an emerging field of inquiry that seeks to strengthen connections between research, policy and practice across sectors, disciplines and countries, attempting to harness the benefits of research for organisational and societal improvement [1]. Challenges of KM between communities of researchers and practitioners have been of particular concern within healthcare research and policy, with a number of terms, such as knowledge utilisation, knowledge transfer, knowledge translation and knowledge exchange, used to describe the process of bridging the 'gap' between research and practice $[2,3]^{\mathrm{a}}$. KM activities often take the form of relatively short-term projects dependent on limited funding, which raises issues about the long-term sustainability of KM and quality improvement designed, facilitated and supported by these initiatives within healthcare organisations $[4,5]$. In the light of this, it is becoming increasingly recognised that the translation of research evidence into practice undertaken by KM initiatives has to be supported by developing the internal capacity of healthcare organisations to engage with and apply research, with 'capacity building' seen by many as one of the key aims of KM [6-10].

At the same time, most of existing health services research literature on capacity building tends to focus on developing skills needed to undertake research projects, with the development of skills required to successfully utilise research in clinical practice and quality improvement receiving relatively less attention (see [11-16] as examples of previous empirical and conceptual work in this area). Often, this literature does not explicitly link with broader social science and management theories exploring the complex, context-dependent and powerladen nature of learning within and between professional and organisational groups (see [17-20] for the importance of theory in KM research and practice). Drawing on empirical and theoretical literature on organisational capabilities and organisational learning, this paper advocates a practice-based, multilevel approach to capacity building through developing relevant capabilities at different levels of complexity. It proposes a number of theory-informed principles that could be useful for guiding intentional capacity building in healthcare organisations which is orchestrated by various KM initiatives undertaken by health professional associations [13], research foundations [21,22], knowledge brokering programmes and networks [23-25] and collaborative partnerships bringing together healthcare professionals, researchers and KM experts [26-31] $]^{\mathrm{b}}$.

The discussion is structured in the following way. The first section clarifies the definition of capacity building for KM, conceptualises capacity building as the process of developing skills, or capabilities, and proposes a typology of capabilities for KM. The second section uses the literature on dynamic capabilities to discuss mechanisms of capacity building at organisational level of analysis and various contextual factors influencing this process. The third section draws on the literature on intra-organisational learning to reflect on the interplay between individual, group and organisational levels of capability development within healthcare organisations. Four principles of the practice-based, multilevel approach to capacity development for KM advocated by the paper are formulated in the fourth section. The concluding section reiterates the key messages of the paper, presents the implications for evaluating capacity building programmes, discusses the limitations of the authors' approach and suggests potential avenues for future research.

\section{Discussion}

\section{Defining and classifying capacity building for KM}

The notion of capacity building entered the academic international aid and development discourse in the 1970s [32] and has since spread to other domains, including public sector management and related disciplines [33]. Initially associated with achieving macro-economic growth in the developing world through 'institution building' and technological transfer, capacity building activities are now increasingly applied to individuals, organisations and communities and broadly refer to the creation, expansion or upgrading of a stock of desired qualities and features called capabilities that could be continuously drawn upon over time [34]. Health services research literature predominantly discusses research capacity building which is defined as 'a process of individual and institutional development which leads to higher levels of skills and greater ability to perform useful research' [35], with most commonly accepted outcomes including publications, conference presentations, successful grant applications and qualifications obtained [36]. Research capacity building, due to an acknowledged gap between producers and users of research [37], may not necessarily directly translate into improved outcomes for health services and patient care unless supported by an appropriate context-specific strategy for KM [38]. However, in focusing on research production, the notion of research capacity building does not explicitly take into account the importance of developing capabilities specific for research implementation, service improvement and KM.

This paper specifically focuses on capacity building for $K M$ in healthcare organisations, which includes implementation of research evidence in practice. Drawing on the concept analysis of capacity building undertaken by Condell and Begley [39], we propose the following definition:

Capacity building for KM is a dynamic activity that augments capabilities to carry out functions or achieve objectives of KM programmes over the long 
term, leading to an improved provision of evidencebased healthcare.

A number of authors $[32,40]$ have shown that the concept of capacity building overlaps with the notion of sustainable change, which refers to the continual presence in an organisation of all or most of the practices/activities of an intervention or programme [41]. While the comparison of these two theoretical concepts lies beyond the scope of this paper, it needs to be highlighted that capacity building focuses on developing individual and organisational capabilities, emphasises the dynamic nature of the process and underscores an ability to apply acquired capabilities to new clinical and improvement issues, challenges and targets [32].

Previous research has shown that skills in collecting, appraising and disseminating research evidence are not enough for transforming research knowledge into clinical action $[42,43]$ and need to be accompanied by an understanding of professional behaviour [44,45], local context $[46,47]$ and facilitation techniques $[48,49]$. Practical implementation of healthcare KM initiatives, therefore, requires a wide range of capabilities that can be categorised into several overlapping knowledge domains, such as personal and organisational development, change management and diffusion of innovation [11] (Table 1).

Organisational capacity to utilise research includes not only locating, obtaining and assessing the quality and relevance of research, but also 'organizational processes related to internalization, transformation and adaptation of research findings' [13]. To unpack the notion of organisational capacity for $\mathrm{KM}$, the typology presented in Table 1 can be usefully complemented by an alternative categorisation of organisational capabilities according to their level of complexity [50] (Table 2), which is informed by the theoretical approach known as the resource-based view of the firm [51-53]. In the context of KM, first-order (ordinary) capabilities can be seen as an ability to deploy resources (such as time, technology or funds) to achieve relatively simple KM tasks. The emphasis of second-order (core) capabilities is on the integration of resources and ordinary capabilities into more complex KM projects aligned with an organisation's strategic priorities. Finally, third-order (dynamic) capabilities denote an organisation's ability to generate, extend and modify its lower-order capabilities to improve effectiveness and respond to the changing environment [54-56]. These may include, for instance, adapting existing KM projects to the changing context; absorbing, assimilating and exploiting KM skills acquired from external organisations and projects; and reconfiguring available skills and resources in order to generate new, innovative KM activities.

The interplay between different levels of KM capabilities can be illustrated by the following example from our previous research $[58,59]$ :

Primary-care-based multiprofessional teams, comprising a general practitioner, nurse and practice manager, worked on a project aiming to improve identification and management of patients with chronic kidney disease (CKD). Supported by external

\section{Table 1 Classification of KM capabilities according to knowledge domains}

\begin{tabular}{|c|c|}
\hline Knowledge domain & Examples \\
\hline \multirow[t]{2}{*}{ 1. Evidence management skills } & - searching, appraising, storing and retrieving research evidence \\
\hline & - synthesising research evidence \\
\hline \multirow[t]{2}{*}{ 2. Process and system thinking } & - ability to apply improvement methodology to address an issue \\
\hline & - ability to 'diagnose' the broader context \\
\hline \multirow[t]{2}{*}{ 3. Personal and organisational development } & - theory and practice of group facilitation \\
\hline & - stakeholder management and influencing skills \\
\hline \multirow[t]{2}{*}{ 4. Involving patients, users, carers, staff and public } & - service redesign based on patient and staff experience \\
\hline & - identifying and acting upon stakeholders' views and needs \\
\hline \multirow[t]{2}{*}{ 5. Change management } & - project and programme management skills \\
\hline & - evaluating impact and learning \\
\hline \multirow[t]{2}{*}{ 6. Delivering on cost and quality } & - financial projection and calculation \\
\hline & - measuring cost-effectiveness \\
\hline \multirow[t]{2}{*}{ 7. Problem solving/consultancy } & - problem identification, definition and structuring \\
\hline & - written and visual presentation of data and recommendations \\
\hline \multirow[t]{2}{*}{ 8. Diffusion of innovation } & - assessing and evaluating potential innovations \\
\hline & - building innovation into service improvement approaches \\
\hline
\end{tabular}


Table 2 Classification of capabilities according to the level of complexity [50]

\begin{tabular}{|c|c|c|c|}
\hline Level & $\begin{array}{l}\text { Type of } \\
\text { capabilities }\end{array}$ & Definition & Examples related to $\mathrm{KM}$ \\
\hline \multirow[t]{3}{*}{ Zero-order } & \multirow[t]{3}{*}{ Resources } & \multirow{3}{*}{$\begin{array}{l}\text { Stocks of available factors that are owned } \\
\text { or controlled by the organisation [57] }\end{array}$} & Access to evidence \\
\hline & & & $\begin{array}{l}\text { Protected time of the clinical staff to get involved in } \\
\text { service improvement }\end{array}$ \\
\hline & & & Funds provided by external KM programmes \\
\hline First-order & Ordinary capabilities & $\begin{array}{l}\text { Abilities to deploy resources to fulfil relatively } \\
\text { simple tasks }\end{array}$ & $\begin{array}{l}\text { Using a case-finding tool to identify all patients with a } \\
\text { certain chronic condition in the general practice system }\end{array}$ \\
\hline Second-order & Core capabilities & $\begin{array}{l}\text { Bundles of an organisation's resources and } \\
\text { first-order capabilities which are strategically } \\
\text { important to achieving its objectives at a } \\
\text { certain point in time }\end{array}$ & $\begin{array}{l}\text { Undertaking audit and feedback of chronic disease registers } \\
\text { in order to improve evidence-based management of patients } \\
\text { and increase financial gains of the general practice }\end{array}$ \\
\hline \multirow[t]{3}{*}{ Third-order } & \multirow[t]{3}{*}{ Dynamic capabilities } & \multirow{3}{*}{$\begin{array}{l}\text { Abilities to constantly integrate, reconfigure, } \\
\text { renew and reconstruct an organisation's } \\
\text { resources and core capabilities in response } \\
\text { to the changing environment }\end{array}$} & $\begin{array}{l}\text { Ability to change the way audit and feedback is conducted } \\
\text { in response to the changing research evidence and/or } \\
\text { performance targets }\end{array}$ \\
\hline & & & $\begin{array}{l}\text { Ability to incorporate new research evidence, health } \\
\text { improvement methodologies and other forms of knowledge } \\
\text { to modify existing and design new KM projects }\end{array}$ \\
\hline & & & $\begin{array}{l}\text { Ability to design a new register verification tool enabling a } \\
\text { quicker and hence more cost-effective way of conducting } \\
\text { audit and feedback }\end{array}$ \\
\hline
\end{tabular}

knowledge mobilisation experts, members of these teams not only developed lower-order, project-related capabilities (such as verifying the CKD practice registers using the latest guidelines), but were also able to integrate them into a more generic secondorder capability of conducting audit informed by improvement methodologies [27]. As a result of developing third-order, dynamic capabilities (such as the ability to transfer learning across teams and the ability to adapt to external change), improvements in some general practices occurred even in areas not related to the initial focus on CKD. These positively affected other disease registers, overall communication within the practice and procedures for the updating of treatment protocols.

The next section will use insights from literature on dynamic capabilities to explore the mechanisms underpinning the development of KM capabilities in healthcare organisations and discuss contextual factors that can influence this process.

\section{Mechanisms of capability development in organisational context}

The following subthemes can be identified from the literature.

\section{Repeated use of capabilities in practice}

Both lower-order and higher-order capabilities strengthen with repeated use [60]. Higher-order capabilities are affected by and operate on lower-order capabilities: the former are often combinations of simpler, foundational capabilities that must be learned first $[53,60]$. Repeated practice (which can be codified in the form of technology and formal procedures) and learning from past mistakes are seen as important mechanisms underpinning the evolution of capabilities [53,61]. It should however be noted that the repeated use of lower-order capabilities without change, i.e. without developing higher-order, dynamic capabilities, may render lower-order capabilities more difficult to change in the future, with an organisation becoming trapped in existing ways of doing things [60,61]. For instance, drawing on the examples presented in Table 2, it could be argued that an ability to perform casefinding on a practice register for a certain condition (an ordinary capability) will only lead to the identification of appropriate cases in the long run if accompanied by an ability to regularly update the case-funding algorithm in line with changing research evidence and diagnostic criteria (a dynamic capability). On the other hand, developing and using dynamic capabilities is costly in the short term as it involves the consumption of organisational resources in integrating, reconfiguring and altering existing lowerorder capabilities [60].

\section{Combining acquisitive and experience-based learning}

It has been suggested that the development of capabilities is governed by two distinct but complementary learning processes [61,62]:

- Acquisitive learning, which occurs when an organisation acquires and internalises knowledge 
from other organisations, new employees and external consultants or by systematically scanning the environment for relevant information;

- Experience-based learning, which happens internally and generates new knowledge that is distinctive to the organisation; it can happen through improvisation, trial and error and experimentation.

Although acquisitive learning plays an important role during early stages of capability formation by providing innovative insights and new opinions, what is learned from others needs to be connected with existing organisational capabilities, structures and processes. Refining, developing and adapting capabilities to the specific organisational contexts are best achieved through experiencebased learning, i.e. learning-by-doing, its quality being dependent on the amount of effort spent on analysing the experience obtained from past cases and capturing the lessons learnt [61].

\section{An interplay between tacit and explicit knowledge}

Developing organisational capabilities involves a two-way relationship between explicit and tacit knowledge [63]. Explicit, articulated, codified knowledge (sourced, for instance, from outside an organisation) needs to be fed into organisational members, applied in practice and made tacit. At the same time, organisational capabilities can also be preserved in the less explicit forms, such as history, norms, beliefs and values that are conveyed to a succession of organisational members through early socialisation and longer-term accumulated social interactions [64,65]. To become more readily available to organisational members, the tacit, unspoken, taken-for-granted components of experience-based knowledge often need to be formalised through the processes of articulation and codification [54]. Knowledge articulation refers to the process by which individuals make their tacit experiential knowledge explicit by expressing their opinions and beliefs, engaging in constructive confrontations and challenging each other's viewpoints. Knowledge codification is a step beyond knowledge articulation and involves individuals codifying their understanding of internal organisational processes in the form of manuals, protocols, decision support systems and other written and electronic tools. It is important to remember, however, that an over-reliance on articulated and codified knowledge can limit responsiveness to the everchanging context and impair the realisation of dynamic capabilities in practice if used without reflection [61]. Keil [61] suggests that articulation and codification as learning mechanisms should be complemented by knowledge exchange through social networks that can be intraorganisational or cut across organisational boundaries and can be based both on informal relationships and formal events.

\section{Moderating influence of organisational context}

Management literature on capability development and health literature on research capacity building identify a number of contextual factors that influence the process of learning new skills in organisations. Some of these factors refer to organisational features, such as organisational culture and attitudes to change and learning [54,66,67]; senior management support of learning and capability development $[12,68,69]$; the presence of a coherent change strategy [47,70]; distributed leadership with credible opinion leaders; and good relationships between managers and clinicians $[47,71]$. Existing knowledge and capacity in a given area are seen as an advantage for further capacity building [66], with many organisations which successfully participate in quality improvement initiatives demonstrating a strong preexisting orientation towards innovation, improvement and change [72]. Participation in effective networks, partnerships and collaborations can also influence organisational learning and capacity building $[36,40,69]$. Finally, developing capabilities requires investing resources, for instance allocating protected time for staff to engage in activities leading to capacity building [68] or putting in place appropriate award systems [69].

To conclude, capability development in organisations happens through repeated practice and involves an integration of acquisitive learning, i.e. getting ideas from the outside, and experience-based learning, which happens internally. An integration of acquisitive and experiencebased learning within organisations is aided by the mechanisms of knowledge articulation, codification and exchange, whereby newly developed capabilities get refined, modified and spread across the whole organisation. The process of capability development within organisations is also highly contingent on the organisational features, resource endowments and starting learning positions, all of which vary widely across organisations. As can also be inferred from this section, literature on dynamic capabilities deploys organisation as the main unit of analysis. Less emphasis has been put here on the intra-organisational processes of intentional capacity building induced by external KM initiatives with which healthcare organisations collaborate. The next section will try to address this gap by exploring the literature on intra-organisational learning, specifically focusing on the interplay between individual, group and organisational levels of capability development.

\section{Individual, group and organisational levels of capability development}

Intentional capacity building undertaken by $\mathrm{KM}$ initiatives in healthcare organisations needs to be analysed as integration of existing organisational capabilities and the developmental input offered by external KM experts. This integration implies a combination of ongoing experiencebased learning taking place within a healthcare organisation 
and acquisitive learning through which an organisation acquires new resources and capabilities from a KM initiative. This process is not conflict-free and often requires formal (e.g. strategic planning and resource allocation procedures) and informal (e.g. negotiating and mediating) efforts to resolve disagreements about the nature and scope of capabilities to be developed, resources to be allocated and priorities to be selected [60,73]. In addition to broader contextual factors described in the previous section, the process of integration is affected by the fact that quality improvement, health promotion and other KM activities often take the form of separate, time-limited projects with clearly defined targets and outcomes, rather than ongoing long-term or integrated programmes of work $[4,74]$. This raises a question about the extent of organisational learning from standalone projects [75-77].

Building on previous literature on capacity building in health services research [36,78] and our own experience $[58,59,79,80]$, we suggest that capability development at the interface between a healthcare organisation and a KM initiative can unfold in three 'configurations': individualcentred, team-centred and organisation-centred (Table 3). These differ by the 'entry point' that the KM initiative uses to tap into the internal processes within a healthcare organisation.

Although the literature on capacity building in healthcare advocates a 'whole of organisation' approach that integrates all levels of capacity building [69,81], this tends to be more resource-intensive than individual- and team-centred approaches. Arguably, it is more likely to succeed in relatively small organisations with a longterm strategic orientation to learning and improvement, established intra-organisational channels of communication and absence of strong intra-organisational barriers $[59,67]$. On the other hand, using individual- and teamcentred approaches to capacity building raises questions about the subsequent assimilation of acquired knowledge and capabilities (i.e. individual and team learning) into broader organisational learning, which is a nested phenomenon occurring at several different but interrelated levels at the same time, whereby learning at one level may substitute for, trade off against or even inhibit learning at another $[76,82]^{\mathrm{c}}$.
Capabilities may be acquired individually but the knowledge of what constitutes 'acceptable' practice is developed and negotiated collectively within a group or community [65,83-85]. At the same time, knowledge that is uniquely possessed by a member is less likely to be mentioned, repeated and attended to in group discussions than commonly held 'collective' knowledge [86]. As a result, organisations do not always 'know what they know': organisational members with information needs are frequently unaware of the existence of knowledge held by other members [87] and individual-centred capability development may become 'stockpiled' if the organisation has a limited capacity to absorb the learning [88]. Similarly, integration of team-specific knowledge and skills into the learning of the whole organisation may be hampered by divisional, departmental, and other intraorganisational barriers to knowledge sharing [59,89-91]. Learning within project teams may not translate into learning between project teams that can enhance organisational learning [75-77].

Moving from individual to group to organisational learning involves continuing conversations among organisational members, participation in shared practices, institutionalisation of capabilities in the systems, structures, strategy and routines and investments in information systems and infrastructure $[86,88]$. When facilitating the transitions between different levels of capability development, two tensions may emerge. First, learning by doing often tends to be favoured over learning from others, especially if the 'others' are unknown [92], which underscores the importance of relationships between the facilitators coming from external KM initiatives (especially where they are not known to the organisation previously) and practitioners working within healthcare organisations. In addition, organisational learning involves a tension between the embedded institutionalised learning from the past and the newly acquired learning [88,93]. Capability development within organisations with a high degree of institutionalised learning can thus require the unlearning of previously established ways of doing things which have become irrelevant and counterproductive [16,94]. At the individual and group levels, this could be facilitated through training, mentoring or reflection while organisational

Table 3 Approaches to capability development in healthcare organisations undertaken by external KM initiatives

\begin{tabular}{|c|c|c|}
\hline Starting point & Description & Example \\
\hline 1. Individual-centred & $\begin{array}{l}\text { An individual based in a healthcare organisation is } \\
\text { supported by or embedded into an external KM team }\end{array}$ & $\begin{array}{l}\text { Training and supporting secondary care based heart failure } \\
\text { nurses to undertake audit and feedback of heart failure care } \\
\text { facilitated by a KM team in general practices [80] }\end{array}$ \\
\hline 2. Team-centred & $\begin{array}{l}\text { A team based in a healthcare organisation is working } \\
\text { on a KM project supported by an external KM initiative }\end{array}$ & $\begin{array}{l}\text { Training and supporting a multiprofessional team to undertake } \\
\text { an evidence-based improvement project around identification } \\
\text { and management of patients with CKD }[58,59]\end{array}$ \\
\hline 3. Organisation-centred & $\begin{array}{l}\text { The whole organisation is involved in one or several } \\
\text { KM projects supported by an external KM team }\end{array}$ & $\begin{array}{l}\text { Supporting all staff members of a general practice (i.e. not just a } \\
\text { nominated 'lead' or 'improvement team') to actively participate } \\
\text { in service improvement projects facilitated by KM experts }\end{array}$ \\
\hline
\end{tabular}


unlearning may involve restructuring and implementing new performance management, communication or resource allocation systems [95].

\section{Rethinking capacity building for KM: lessons for KM initiatives}

In light of the analysis presented in the previous three sections, we suggest the following four principles underpinning a practice-based approach to developing multilevel KM capabilities in healthcare.

\section{From 'building' towards 'developing' capacity}

We suggest that 'developing' capacity may be a better term than 'building' capacity for the following reasons. Whilst the 'building' metaphor puts an emphasis on the creation of new capabilities undertaken by KM initiatives for the participating healthcare organisations, the notion of 'capability development' underscores the expansion and upgrade of the capabilities already existing in healthcare organisations. It could be argued that embarking on an externally supported KM programme already signifies an interest in procuring external knowledge to improve everyday practice, which can be interpreted as an innovative capability [72]. Similarly, through their previous experience, healthcare organisations already possess a wide array of ordinary and core capabilities that may be renewed, reconfigured and integrated in the process of KM. In addition, even though an external KM project can introduce some completely new skills to a healthcare organisation, they still need to be assimilated into the existing organisational routines, which includes modification and adaptation of externally acquired knowledge to local contexts. This process is affected by multiple factors, some of which (e.g. resources and facilitation) are more amenable to control by an external KM initiative than others (e.g. organisational culture and leadership) (see also [40]). The role of a KM initiative is, therefore, to tap into existing organisational capabilities and attempt to develop them by offering relevant skills, tools and resources, rather than build new skills in healthcare staff that may remain unused and lost after the project is completed.

\section{From passive recipients towards active participants}

Although formal training in quality improvement and KM can be an important component of capacity development, it will only be effective if directly connected with everyday practice $[11,74]$, with learning by doing or, in this context, 'learning by practising KM', acting as the main mechanism of learning taking place at the interface of a healthcare organisation and a KM initiative. In order for KM capabilities to be developed in healthcare organisations, healthcare professionals should be actively involved in KM projects as implementers of change, rather than act as passive recipients of change introduced by external KM experts. The role of the latter in the process of facilitating capacity development in healthcare organisations is the following:

- Providing resources (e.g. buying out clinicians' time);

- Creating opportunities for healthcare staff to improvise, experiment and learn from mistakes whilst engaging in the practice of $\mathrm{KM}$;

- Creating opportunities for healthcare staff to come together to exchange knowledge between individuals, groups and organisations;

- Providing continuous mentorship and support to healthcare staff;

- Providing specialist expertise when needed (e.g. complex data analysis techniques);

- Introducing theoretical and methodological tools, frameworks and ideas that can help healthcare staff to reflect on their practice and achieve an integration of old and new knowledge and skills (this is discussed in more detail in the following two subsections).

\section{From lower-order towards higher-order capabilities}

When KM projects tend to focus on a certain topic and have well-defined targets and outcomes, there is a risk that capabilities developed through participation in the project will remain project-specific and will not be transferred to other areas. In addition to project-specific, lower-order capabilities, emphasis should be put on the development of more generic, dynamic capabilities, i.e. an ability to change lower-order capabilities and thus better adapt to change, absorb external knowledge and innovate. As argued in the management literature [50,52,54,56,60], dynamic capabilities are especially important for organisations located in rapidly changing environments, of which a healthcare system could be an example [96]. KM initiatives can therefore enhance their effectiveness in a number of ways:

- Introducing healthcare staff to quality improvement methodologies and theories of change and innovation which, if continuously applied in practice, may enable the process of knowledge articulation seen as a prerequisite for the formation of dynamic capabilities;

- Supporting the process of knowledge codification, whereby generic lessons learnt throughout the KM project are summarised in the form of organisational manuals, toolkits and protocols, and helping healthcare organisations integrate these into their day-to-day routines in a reflective and context-sensitive way;

- Helping healthcare staff to reflect on the contextual features of their organisation, to use organisational 
channels of communication (such as meetings, newsletters or informal chats) for the sharing of KM-related knowledge and to utilise the relevant capabilities in other areas of work throughout the organisation.

\section{From single-level towards multilevel learning}

To maximise the effectiveness of intentional capacity building in healthcare organisations, KM initiatives must take into account the mechanisms that allow transitioning between individual, group and organisational learning. Regardless of the point of contact between a KM initiative and a healthcare organisation, it is important to pay attention to different levels of learning within the healthcare organisation. The following transitions may require support or facilitation:

- Individual to group level of capability developmentenabling the spread of learning from individuals to groups;

- Group to organisational level of capability development-enabling the spread of learning between different groups and from groups to the broader organisation;

- Organisational to individual level of capability development-enabling the spread of institutionalised organisational learning to new organisational members $^{\mathrm{d}}$ (Table 4).

In addition to supporting the interpretation, integration and institutionalisation of KM knowledge and skills, the following steps could be taken by KM facilitators to support multilevel capability development in healthcare organisations:

- Information about ongoing KM work (what, how and by whom is being done) should be widely distributed across a healthcare organisation because information distribution leads to more broadly based organisational learning [87];

- When planning for knowledge sharing within an organisation, emphasis needs to be placed on encouraging individuals and teams involved in KM projects to articulate how they have achieved their goals, not only what they have achieved, i.e. on procedural knowledge rather than product knowledge [92];

- When spreading KM skills and knowledge across an organisation, intermediaries could be involved: those who connect the external KM facilitators with different professional groups within an organisation [97], formally oversee several different teams [98] or fulfil an informal knowledge brokering role between different intra-organisational groups $[99,100]$.

\section{Conclusion}

The four principles outlined above can be useful for a range of KM initiatives, such as Collaborations for Leadership in Applied Health Research and Care (CLAHRCs) [101] and Academic Health Science Networks (AHSNs) [102] in England; the Knowledge Network in Scotland [25]; the Accreditation Collaborative for the Conduct of

\section{Table 4 Facilitating the transitions between different levels of learning within a healthcare organisation}

\begin{tabular}{|c|c|}
\hline Area & Actions to be considered by the facilitators \\
\hline \multirow[t]{4}{*}{ Transition from the individual to group level of learning } & - Involving multiprofessional teams in KM projects \\
\hline & $\begin{array}{l}\text { - Encouraging the discussions of KM projects at formal and informal team } \\
\text { meetings and other events }\end{array}$ \\
\hline & $\begin{array}{l}\text { - Using individual skills and knowledge to develop wider KM activities } \\
\text { involving more staff }\end{array}$ \\
\hline & $\begin{array}{l}\text { - Enabling individual organisational members to act as educators for the } \\
\text { rest of the organisational staff }\end{array}$ \\
\hline \multirow[t]{4}{*}{ Transition from the group to organisational level of learning } & - Rotating organisational members between different teams and departments \\
\hline & $\begin{array}{l}\text { - Identifying and engaging individuals acting as intermediaries between } \\
\text { different teams/departments }\end{array}$ \\
\hline & - Helping KM teams present their work to the wider organisation \\
\hline & $\begin{array}{l}\text { - Institutionalising knowledge and skills in the form of organisational protocols, } \\
\text { procedures and reminders }\end{array}$ \\
\hline \multirow[t]{4}{*}{ Transition from the organisational to individual level of learning } & - Recruiting more staff from across an organisation to take part in KM activities \\
\hline & $\begin{array}{l}\text { - Creating opportunities for new staff to shadow more experienced } \\
\text { organisational members }\end{array}$ \\
\hline & - Raising awareness about the location of relevant KM skills within an organisation \\
\hline & $\begin{array}{l}\text { - Updating protocols and procedures in the light of the new knowledge } \\
\text { and skills acquired by an organisation }\end{array}$ \\
\hline
\end{tabular}


Research, Evaluation and Designated Investigations through Teamwork (ACCREDIT) [103] in Australia; and Knowledge Translation Canada [104]. Table 5 presents the key questions to be addressed when implementing these principles in practice.

This paper calls for a shift from a focus on the content of capacity building programmes (i.e. what topics should be covered and what capabilities have to be developed) towards a more strategic thinking about the subsequent 'life' of these capabilities within a recipient healthcare organisation (i.e. how these knowledge and skills will be utilised, maintained and updated as part of organisational ways of doing things). We have emphasised the importance of integrating 'learning from others', through which healthcare organisations acquire knowledge and skills from KM experts, and 'learning by doing', through which healthcare organisations adapt, absorb and modify their knowledge and capabilities through repeated practice. We have also proposed that capacity building activities should go beyond supplying a range of training opportunities to healthcare staff and incorporate an active facilitation of the processes by which newly acquired knowledge and capabilities are going to be integrated into the wider organisation, involving the transitions between individual, group and organisational learning.

A detailed exploration of criteria to be used when monitoring and assessing capacity development in healthcare organisations involved in KM programmes lies beyond the scope of this paper. However, our analysis has a number of implications for theory-informed evaluations of capacity

\section{Table 5 Questions to be addressed when applying the principles of KM capability development in practice}

\begin{tabular}{|c|c|}
\hline Principle & Questions to be addressed \\
\hline \multirow[t]{5}{*}{$\begin{array}{l}\text { 1. Moving from 'building' capacity from scratch towards 'developing' } \\
\text { capacity of healthcare organisations }\end{array}$} & $\begin{array}{l}\text { - What existing knowledge and skills within a healthcare organisation } \\
\text { could be utilised for KM projects? }\end{array}$ \\
\hline & -Where in the organisations are these knowledge and skills located? \\
\hline & - How can these knowledge and skills be further developed? \\
\hline & $\begin{array}{l}\text { - What KM skills are currently lacking and how can their development } \\
\text { be supported? }\end{array}$ \\
\hline & $\begin{array}{l}\text { - How will the newly acquired knowledge and skills integrate with } \\
\text { existing ways of doing things within an organisation? }\end{array}$ \\
\hline \multirow{5}{*}{$\begin{array}{l}\text { 2. Moving from passive involvement in formal education and training } \\
\text { towards active, continuous participation in KM practices }\end{array}$} & - What KM activities are the staff actively involved in? \\
\hline & $\begin{array}{l}\text { - How are the roles distributed between the external facilitators and } \\
\text { the local staff involved in KM projects? }\end{array}$ \\
\hline & $\begin{array}{l}\text { - What arrangements are in place to enable the facilitative role of } \\
\text { external KM experts? }\end{array}$ \\
\hline & $\begin{array}{l}\text { - What incentives can be provided to support the engagement of } \\
\text { local staff in KM activities? }\end{array}$ \\
\hline & - What mentorship and shadowing options are available for healthcare staff? \\
\hline \multirow[t]{5}{*}{$\begin{array}{l}\text { 3. Moving from lower-order, project-specific capabilities towards } \\
\text { higher-order, generic capabilities }\end{array}$} & $\begin{array}{l}\text {-What mechanisms will ensure maintenance and further development } \\
\text { of capabilities within an organisation? }\end{array}$ \\
\hline & $\begin{array}{l}\text { - How will project-specific knowledge and skills be transferred to other } \\
\text { areas of practice? }\end{array}$ \\
\hline & $\begin{array}{l}\text { - What theoretical models, frameworks and approaches can be useful } \\
\text { to guide the local development of KM capabilities? }\end{array}$ \\
\hline & $\begin{array}{l}\text { - What are the arrangements for updating organisational protocols, } \\
\text { guidelines and procedures related to KM? }\end{array}$ \\
\hline & $\begin{array}{l}\text { - What are the arrangements for identifying new learning opportunities } \\
\text { outside an organisation? }\end{array}$ \\
\hline \multirow[t]{5}{*}{$\begin{array}{l}\text { 4. Moving from single-level towards multilevel learning about KM } \\
\text { within healthcare organisations }\end{array}$} & $\begin{array}{l}\text { - How do the capabilities developed by individual and teams link with } \\
\text { organisational priorities? }\end{array}$ \\
\hline & $\begin{array}{l}\text { - What are the intra-organisational boundaries to sharing knowledge } \\
\text { and skills and how are these boundaries going to be addressed? }\end{array}$ \\
\hline & $\begin{array}{l}\text { - How is sharing knowledge and skills within the project team and } \\
\text { between the teams going to be supported? }\end{array}$ \\
\hline & $\begin{array}{l}\text { - What mechanisms are in place to ensure the unlearning of irrelevant } \\
\text { knowledge? }\end{array}$ \\
\hline & $\begin{array}{l}\text { - What arrangements are in place to ensure that the whereabouts of } \\
\text { relevant knowledge and skills in an organisation are known to its members? }\end{array}$ \\
\hline
\end{tabular}


development. The outcomes of developing KM capabilities, i.e. acquired capabilities and resulting organisational change, are difficult to quantify, while such measures as the number of KM projects undertaken by the staff or the number of individuals trained are unlikely to capture the 'soft' and complex nature of capacity development. A range of qualitative process descriptors should therefore be deployed, with their selection driven by the local context of KM, taking into account the following dimensions:

- Evidence of KM skills developed through practice;

- Ability to independently exercise, develop and modify these skills after the project is over;

- Applicability of the capabilities developed in a certain project to other projects or clinical areas;

- Uptake of capabilities developed by individuals and teams across the whole organisation;

- Impact of the capabilities on organisational strategy, culture and procedures.

Whilst developed from previous research in related areas, the analysis presented in this paper and our conclusions must be regarded as tentative until corroborated by rigorous empirical evidence. The paper limits the discussion of capacity building to capabilities, i.e. skills, whereas capacity building tools, infrastructure, systems and roles [105] have not been explicitly addressed. Its focus is on developing capabilities in healthcare organisations, while capacity development within KM initiatives supporting these organisations has not been discussed and can provide an interesting direction for future research. Other topics for empirical explorations may include: the comparative effectiveness of different strategies aiming to facilitate the transition between individual, group and organisational learning; the relationship between individual characteristics of healthcare and KM staff (e.g. their confidence, status, legitimacy or position in organisational and professional networks) and the trajectories of KM capability development; and the interplay between capability development in healthcare organisations and the type and scope of facilitation approach chosen by the external KM initiative.

\section{Endnotes}

${ }^{a}$ Following Ferlie and colleagues [20], we prefer the term ' $\mathrm{KM}$ ' to other related concepts (e.g. 'knowledge management', knowledge transfer', 'research utilisation', etc.) because it is looser and signals possible resistance or unplanned outcomes (such as, for instance, the formation of cross-project barriers to learning within KM initiatives [89]).

${ }^{\mathrm{b}}$ Intentional capacity building activities are specifically designed to develop relevant knowledge and skills, whereas unintentional capacity building refers to learning benefits accrued in a more random way by virtue of participation in a KM programme [106].

${ }^{\mathrm{c}}$ Mechanisms enabling the transitions between individual, team and organisational levels of learning are not dissimilar to the fundamental mechanisms underpinning the formation of dynamic capabilities explored in the previous section-see, for instance, Newell and Edelman [98], who conceptualise cross-project learning as a dynamic capability.

${ }^{\mathrm{d}}$ Moving from organisational to individual level of learning is mediated by the group level and involves the conversion of explicit knowledge into tacit through dialogue and shared practice [88] discussed earlier.

Competing interests

The authors declare that they have no competing interests.

\section{Authors' contributions}

All authors contributed to the conception and design of the paper. RK conducted the review of the literature and drafted the manuscript. $\mathrm{HW}, \mathrm{GH}$ and RB critically revised the manuscript. All authors read and approved the final manuscript.

\section{Acknowledgements}

We acknowledge the support of the National Institute for Health Research Collaboration for Leadership in Applied Health Research and Care (NIHR CLAHRC) Greater Manchester. The views expressed are those of the authors and not necessarily those of the NHS, the NIHR or the Department of Health. We are also grateful to Professor Graham Martin and Dr. Reece Hinchcliff, who acted as reviewers for this paper, for their insightful comments.

\section{Author details}

${ }^{1}$ Manchester Business School, The University of Manchester, Room D38 MBS East, Booth Street West, Manchester M15 6PB, UK. ${ }^{2}$ School of Nursing, Midwifery and Social Work, The University of Manchester, Jean McFarlane Building, Oxford Road, Manchester M13 9PL, UK. ${ }^{3}$ School of Nursing, The University of Adelaide, Level 3, Eleanor Harrald Building, Adelaide 5005, SA, Australia.

Received: 16 June 2014 Accepted: 19 September 2014

Published online: 15 November 2014

\section{References}

1. Cooper A, Levin B: Some Canadian contributions to understanding knowledge mobilisation. Evid Policy 2010, 6(3):351-369.

2. Graham ID, Logan J, Harrison MB, Straus SE, Tetroe J, Caswell W, Robinson N: Lost in knowledge translation: time for a map? J Contin Educ Health Prof 2006, 26(1):13-24.

3. Greenhalgh T, Wieringa S: Is it time to drop the 'knowledge translation' metaphor? A critical literature review. JRSM 2011, 104(12):501-509.

4. Bate SP, Robert G: Knowledge management and communities of practice in the private sector: lessons for modernizing the National Health Service in England and Wales. Public Adm 2002, 80(4):643-663.

5. Kislov R, Harvey G, Walshe K: Collaborations for Leadership in Applied Health Research and Care: lessons from the theory of communities of practice. Implementation Sci 2011, 6:64.

6. CLAHRC Partnership Programme. http://www.clahrcpp.co.uk/.

7. Ward V, House A, Hamer S: Knowledge brokering: the missing link in the evidence to action chain? Evid Policy 2009, 5(3):267-279.

8. Bate $P$, Robert $G$, Bevan $\mathrm{H}$ : The next phase of healthcare improvement: what can we learn from social movements? Qual Safety Health Care 2004 13(1):62-66

9. Dobbins M, Robeson P, Ciliska D, Hanna S, Cameron R, O'Mara L, DeCorby K Mercer S: A description of a knowledge broker role implemented as part of a randomized controlled trial evaluating three knowledge translation strategies. Implementation Sci 2009, 4:23. 
10. Mitton C, Adair CE, McKenzie E, Patten SB, Perry BW: Knowledge transfer and exchange: review and synthesis of the literature. Milbank Q 2007, 85(4):729-768

11. Bevan H: How can we build skills to transform the healthcare system? J Res Nurs 2010, 15(2):139-148.

12. Berta W, Teare GF, Gilbart E, Ginsburg LS, Lemieux-Charles L, Davis D, Rappolt S: Spanning the know-do gap: understanding knowledge application and capacity in long-term care homes. Soc Sci Med 2010, 70(9):1326-1334.

13. Hamel N, Schrecker T: Unpacking capacity to utilize research: a tale of the Burkina Faso public health association. Soc Sci Med 2011, 72(1):31-38.

14. Nutley S, Davies HTO: Making a reality of evidence-based practice: some lessons from the diffusion of innovations. Public Money Manage 2000, 20(4):35-42.

15. Nutley S, Walter I, Davies HTO: From knowing to doing: a framework for understanding the evidence-into-practice agenda. Evaluation 2003, 9(2):125-148.

16. Nutley SM, Davies HTO: Developing organizational learning in the NHS. Med Educ 2001, 35(1):35-42.

17. Eccles M, Grimshaw J, Walker A, Johnston M, Pitts N: Changing the behavior of healthcare professionals: the use of theory in promoting the uptake of research findings. J Clin Epidemio/ 2005, 58(2):107-112.

18. Grol RPTM, Bosch MC, Hulscher MEJL, Eccles MP, Wensing M: Planning and studying improvement in patient care: the use of theoretical perspectives. Milbank Q 2007, 85(1):93-138.

19. Oborn E, Barrett M, Racko G: Knowledge translation in healthcare: incorporating theories of learning and knowledge from the management literature. J Health Organ Manag 2013, 27(4):412-431.

20. Ferlie E, Crilly T, Jashapara A, Peckham A: Knowledge mobilisation in healthcare: a critical review of health sector and generic management literature. Soc Sci Med 2012, 74(8):1297-1304.

21. Lavis JN, Robertson D, Woodside JM, McLeod CB, Abelson J: How can research organizations more effectively transfer research knowledge to decision makers? Milbank Q 2003, 81(2):221-248.

22. Lomas J: Using 'linkage and exchange' to move research into policy at a Canadian foundation. Health Aff 2000, 19(3):236-240.

23. van Kammen J, de Savigny D, Sewankambo N: Using knowledge brokering to promote evidence-based policy-making: the need for support structures. Bull World Health Organ 2006, 84(8):608-612

24. CHSRF's Knowledge Brokering Program: A Review of Conditions and Context for Success. Canadian Health Services Research Foundation: Ottawa, ON; 2012

25. Wales A, Graham S, Rooney K, Crawford A: Scotland's knowledge network: translating knowledge into action to improve quality of care. Scott Med J 2012, 57(4):221-224.

26. Phipps DJ, Shapson S: Knowledge mobilisation builds local research collaborations for social innovation. Evid Policy 2009, 5(3):211-227.

27. Harvey G, Fitzgerald L, Fielden S, McBride A, Waterman H, Bamford D, Kislov R, Boaden R: The NIHR Collaboration for Leadership in Applied Health Research and Care (CLAHRC) for Greater Manchester: Combining empirical, theoretical and experiential evidence to design and evaluate a large-scale implementation strategy. Implementation Sci 2011, 6:96.

28. Rowley E, Morriss R, Currie G, Schneider J: Research into practice: Collaboration for Leadership in Applied Health Research and Care (CLAHRC) for Nottinghamshire, Derbyshire, Lincolnshire (NDL). Implementation Sci 2012, 7:40.

29. Baker R, Robertson N, Rogers S, Davies M, Brunskill N, Khunti K, Steiner M, Williams M, Sinfield P: The National Institute of Health Research (NIHR) Collaboration for Leadership in Applied Health Research and Care (CLAHRC) for Leicestershire, Northamptonshire and Rutland (LNR): a programme protocol. Implementation Sci 2009, 4:72

30. Walshe K, Davies HT: Health research, development and innovation in England from 1988 to 2013: from research production to knowledge mobilization. J Health Serv Res Policy 2013, 18(S3):1-12.

31. Hinchcliff $R$, Greenfield D, Braithwaite J: Is it worth engaging in multistakeholder health services research collaborations? Reflections on key benefits, challenges and enabling mechanisms. Int I Qual Health Care 2014, 26(2):124-128

32. Crisp BR, Swerissen $H$, Duckett SJ: Four approaches to capacity building in health: consequences for measurement and accountability. Health Promot Int 2000, 15(2):99-107.

33. Harrow J: 'Capacity building' as a public management goal-myth, magic or the main chance? Public Manage Rev 2001, 3(2):209-230.
34. Paul S: Capacity Building for Health Sector Reform. Geneva: World Health Organization; 1995.

35. Trostle J: Research capacity building in international health: definitions, evaluations and strategies for success. Soc Sci Med 1992, 35(11):1321-1324.

36. Cooke J: A framework to evaluate research capacity building in health care. BMC Fam Pract 2005, 6:44

37. Cooksey D: A Review of UK Health Research Funding. London: The Stationery Office; 2006

38. Ferlie E, Dopson S, Fitzgerald L, Locock L: Renewing policy to support evidence-based health care. Public Adm 2009, 87(4):837-852.

39. Condell SL, Begley C: Capacity building: a concept analysis of the term applied to research. Int J Nurs Pract 2007, 13(5):268-275.

40. Shediac-Rizkallah MC, Bone LR: Planning for the sustainability of community-based health programs: conceptual frameworks and future directions for research, practice and policy. Health Educ Res 1998, 13(1):87-108.

41. Virani $T$, Lemieux-Charles $L$, Davis DA, Berta W: Sustaining change: once evidence-based practices are transferred, what then? Healthc Q 2009, 12(1):89-96.

42. Dopson S, Fitzgerald L, Ferlie E, Gabbay J, Locock L: No magic targets! Changing clinical practice to become more evidence based. Health Care Manage Rev 2002, 27(3):35-47.

43. Fitzgerald L, Ferlie E, Wood M, Hawkins C: Interlocking interactions: the diffusion of innovations in health care. Human Relations 2002, 55(12):1429-1449.

44. Dopson $S$, Fitzgerald $L$ : The role of the middle manager in the implementation of evidence-based health care. J Nurs Manag 2006, 14(1):43-51.

45. Locock L, Dopson S, Chambers D, Gabbay J: Understanding the role of opinion leaders in improving clinical effectiveness. Soc Sci Med 2001, 53(6):745-757

46. Dopson S, Fitzgerald L, Ferlie E: Understanding change and innovation in healthcare settings: reconceptualizing the active role of context. J Change Manage 2008, 8(3):213-231.

47. Fitzgerald L, Ferlie E, Addicott R, Baeza J, Buchanan D, McGivern G: Service improvement in healthcare: understanding change capacity and change context. Clin Manage 2007, 15(2):61-74.

48. Harvey G, Loftus-Hills A, Rycroft-Malone J, Titchen A, Kitson A, McCormack B, Seers K: Getting evidence into practice: the role and function of facilitation. J Adv Nurs 2002, 37(6):577-588,

49. Stetler C, Legro M, Rycroft-Malone J, Bowman C, Curran G, Guihan M, Hagedorn $\mathrm{H}$, Pineros S, Wallace C: Role of 'external facilitation' in implementation of research findings: a qualitative evaluation of facilitation experiences in the Veterans Health Administration. Implementation Sci 2006, 1:23.

50. Wang CL, Ahmed PK: Dynamic capabilities: a review and research agenda. Int J Manage Rev 2007, 9(1):31-51.

51. Ambrosini V, Bowman C: What are dynamic capabilities and are they a useful construct in strategic management? Int J Manage Rev 2009, 11(1):29-49.

52. Barreto I: Dynamic capabilities: a review of past research and an agenda for the future. J Manage 2010, 36(1):256-280.

53. Eisenhardt KM, Martin JA: Dynamic capabilities: what are they? Strateg Managet J 2000, 21(10-11):1105-1121.

54. Zollo M, Winter SG: Deliberate learning and the evolution of dynamic capabilities. Organization Sci 2002, 13(3):339-351.

55. Winter SG: Understanding dynamic capabilities. Strateg Manage J 2003 24(10):991-995.

56. Teece DJ, Pisano G, Shuen A: Dynamic capabilities and strategic management. Strateg Manage J 1997, 18(7):509-533.

57. Amit R, Schoemaker PJH: Strategic assets and organizational rent. Strateg Manage J 1993, 14(1):33-46.

58. Humphreys J, Harvey G, Coleiro M, Butler B, Barclay A, Gwozdziewicz M, O'Donoghue D, Hegarty J: A collaborative project to improve identification and management of patients with chronic kidney disease in a primary care setting in Greater Manchester. BMJ Qual Saf 2012, 21:700-708.

59. Kislov R, Walshe K, Harvey G: Managing boundaries in primary care service improvement: a developmental approach to communities of practice. Implementation Sci 2012, 7:97.

60. Zahra SA, Sapienza HJ, Davidsson P: Entrepreneurship and dynamic capabilities: a review, model and research agenda. J Manage Stud 2006, 43(4):917-955

61. Keil T: Building external corporate venturing capability. J Manage Stud 2004, 41(5):799-825. 
62. Zahra SA, Nielsen AP, Bogner WC: Corporate entrepreneurship, knowledge, and competence development. Entrepreneurship Theory Pract 1999, 23(3):169-189.

63. Tsoukas H, Vladimirou E: What is organizational knowledge? J Manage Stud 2001, 38(7):973-993.

64. Brown JS, Duguid P: Organizational learning and communities-of-practice: toward a unified view of working, learning and innovation. Organization Sci 1991, 2(1):40-57.

65. Lave J, Wenger E: Situated Learning: Legitimate Peripheral Participation. Cambridge: Cambridge University Press; 1991.

66. Cooke J, Nancarrow S, Dyas J, Williams M: An evaluation of the 'Designated Research Team' approach to building research capacity in primary care. BMC Fam Pract 2008, 9:37.

67. Peirson L, Ciliska D, Dobbins M, Mowat D: Building capacity for evidence informed decision making in public health: a case study of organizational change. BMC Public Health 2012, 12:137.

68. Cooke J, Nancarrow S, Hammersley V, Farndon L, Wesley V: The 'Designated Research Team' approach to building research capacity in primary care. Primary Health Care Res Dev 2006, 7(1):78-86.

69. Golenko X, Pager S, Holden L: A thematic analysis of the role of the organisation in building allied health research capacity: a senior managers' perspective. BMC Health Serv Res 2012, 12:276.

70. Pablo AL, Reay T, Dewald JR, Casebeer AL: Identifying, enabling and managing dynamic capabilities in the public sector. J Manage Stud 2007, 44(5):687-708.

71. Fitzgerald L, Ferlie E, McGivern G, Buchanan D: Distributed leadership patterns and service improvement: evidence and argument from English healthcare. Leadersh Q 2013, 24(1):227-239.

72. Walshe K: Pseudoinnovation: the development and spread of healthcare quality improvement methodologies. Int J Qual Health Care 2009, 21(3):153-159.

73. Barney J: Firm resources and sustained competitive advantage. J Manage 1991, 17(1):99-120.

74. Whitelaw S, Graham N, Black D, Coburn J, Renwick L: Developing capacity and achieving sustainable implementation in healthy 'settings': insights from NHS Health Scotland's Health Promoting Health Service project. Health Promot Int 2012, 27(1):127-137.

75. Newell S, Bresnen M, Edelman L, Scarbrough H, Swan J: Sharing knowledge across projects: limits to ICT-led project review practices. Manage Learn 2006, 37(2):167-185.

76. Scarbrough H, Swan J, Laurent S, Bresnen M, Edelman L, Newell S: Projectbased learning and the role of learning boundaries. Organization Stud 2004, 25(9):1579-1600.

77. Swan J, Scarbrough H, Newell S: Why don't (or do) organizations learn from projects? Manage Learn 2010, 41(3):325-344.

78. Bowen S, Martens $P$, The Need to Know Team: Demystifying knowledge translation: learning from the community. J Health Serv Res Policy 2005, 10(4):203-211

79. Kislov R: From a project team to a community of practice? An exploration of boundary and identity in the context of healthcare collaboration. In Patient-Centred Health Care: Achieving Co-ordination Communication and Innovation. Edited by Keating MA, McDermott AM, Montgomery K. Basingstoke: Palgrave Macmillan; 2013:103-118.

80. Tierney S, Kislov R, Deaton C: A qualitative study of a primary-care based intervention to improve the management of patients with heart failure: the dynamic relationship between facilitation and context. BMC Fam Pract 2014, 15:153.

81. Farmer $\mathrm{E}$, Weston $\mathrm{K}$ : A conceptual model for capacity building in Australian primary health care research. Aust Fam Physician 2002, 31(12):1139-1142.

82. Levinthal DA, March JG: The myopia of learning. Strateg Manage J 1993 14(S2):95-112

83. Cook SD, Brown JS: Bridging epistemologies: the generative dance between organizational knowledge and organizational knowing. Organization Sci 1999, 10(4):381-400.

84. Wenger E: Communities of Practice: Learning, Meaning and Identity. Cambridge: Cambridge University Press; 1998.

85. Gabbay J, le May A: Practice-Based Evidence for Healthcare: Clinical Mindlines. Oxon: Routledge; 2011.

86. Argote L, McEvily B, Reagans R: Managing knowledge in organizations: an integrative framework and review of emerging themes. Manage Sci 2003, 49(4):571-582
87. Huber GP: Organizational learning: the contributing processes and the literatures. Organization Sci 1991, 2(1):88-115.

88. Crossan MM, Lane HW, White RE: An organizational learning framework: from intuition to institution. Acad Manage Rev 1999, 24(3):522-537.

89. Kislov R: Boundary discontinuity in a constellation of interconnected practices. Public Adm 2014, 92(2):307-323.

90. Szulanski G: Exploring internal stickiness: impediments to the transfer of best practice within the firm. Strateg Manage J 1996, 17:27-43.

91. Powell AE, Davies HTO: The struggle to improve patient care in the face of professional boundaries. Soc Sci Med 2012, 75(5):807-814

92. Newell S: Enhancing cross-project learning. Eng Manage J 2004, 16(1):12-20

93. March JG: Exploration and exploitation in organizational learning. Organization Sci 1991, 2(1):71-87.

94. Tsang EWK, Zahra SA: Organizational unlearning. Human Relations 2008 , 61(10):1435-1462.

95. Rushmer R, Davies HTO: Unlearning in health care. Qual Safety Health Care 2004, 13(suppl 2):ii10-ii15.

96. McMurray R: Our reforms, our partnerships, same problems: the chronic case of the English NHS. Public Money Manage 2007, 27(1):77-82.

97. Kislov R, Boaden R: Hybrid professionals as institutionalised knowledge brokers: limited managerial authority in a constraining context. In 9th International Organisational Behaviour in Healthcare Conference (OBHC). Copenhagen: Copenhagen Business School; 2014.

98. Newell S, Edelman LF: Developing a dynamic project learning and crossproject learning capability: synthesizing two perspectives. Inf Syst J 2008 18(6):567-591

99. Waring J, Currie G, Crompton A, Bishop S: An exploratory study of knowledge brokering in hospital settings: facilitating knowledge sharing and learning for patient safety? Soc Sci Med 2013, 98:79-86.

100. Currie G, White L: Inter-professional barriers and knowledge brokering in an organizational context: the case of healthcare. Organization Stud 2012, 33(10):1333-1361.

101. Collaborations for Leadership in Applied Health Research and Care (CLAHRCs). http://www.nihr.ac.uk/about/collaborations-for-leadership-inapplied-health-research-and-care.htm.

102. Academic health science networks. http://www.nhsinnovationsnorth.org. uk/ahsn/.

103. Braithwaite J, Westbrook J, Johnston B, Clark S, Brandon M, Banks M, Hughes C, Greenfield D, Pawsey M, Corbett A, Georgiou A, Callen J, Øvretveit J, Pope C, Suñol R, Shaw C, Debono D, Westbrook M, Hinchcliff R, Moldovan M: Strengthening organizational performance through accreditation research - $a$ framework for twelve interrelated studies: the ACCREDIT project study protocol. BMC Res Notes 2011, 4:390

104. Knowledge translation Canada. http://ktclearinghouse.ca/ktcanada.

105. Potter C, Brough R: Systemic capacity building: a hierarchy of needs Health Policy Plan 2004, 19(5):336-345.

106. Cousins JB, Goh SC, Elliott CJ, Bourgeois I: Framing the capacity to do and use evaluation. In Organizational Capacity to Do and Use Evaluation. Edited by Cousins JB, Bourgeois I. San Francisco, CA: Jossey-Bass; 2014:7-23.

doi:10.1186/s13012-014-0166-0

Cite this article as: Kislov et al:: Rethinking capacity building for knowledge mobilisation: developing multilevel capabilities in healthcare organisations. Implementation Science 2014 9:166.

\section{Submit your next manuscript to BioMed Central and take full advantage of:}

- Convenient online submission

- Thorough peer review

- No space constraints or color figure charges

- Immediate publication on acceptance

- Inclusion in PubMed, CAS, Scopus and Google Scholar

- Research which is freely available for redistribution 